\title{
Does computer use pose an occupational hazard for forearm pain; from the NUDATA study
}

\author{
A I Kryger, J H Andersen, C F Lassen, L P A Brandt, I Vilstrup, E Overgaard, J F Thomsen, \\ S Mikkelsen
}

Occup Environ Med 2003;60:e14 (http://www.occenvmed.com/cgi/content/full/60/11/e14)

See end of article for authors' affiliations

Correspondence to:

Dr A I Kryger, Department of Occupational Medicine, Copenhagen University

Hospital, Glostrup, Nordre Ringvej, DK-2600 Glostrup, Denmark; akry@dadlnet.dk

Accepted 28 May 2003

\begin{abstract}
Aims: To determine the occurrence of pain conditions and disorders in the forearm and to evaluate risk factors for forearm pain in a cohort of computer workers.

Methods: A total of 6943 participants with a wide range of computer use and work tasks were studied. At baseline and at one year follow up participants completed a questionnaire. Participants with relevant forearm symptoms were offered a clinical examination. Symptom cases and clinical cases were defined on the basis of self reported pain score and palpation tenderness in the muscles of the forearm.

Results: The seven days prevalence of moderate to severe forearm pain was $4.3 \%$. Sixteen of 296 symptom cases met criteria for being a clinical forearm case, and 12 had signs of potential nerve entrapment. One year incidence of reported symptom cases was 1.3\%; no subjects developed new signs of nerve entrapment. Increased risk of new forearm pain was associated with use of a mouse device for more than 30 hours per week, and with keyboard use more than 15 hours per week. High job demands and time pressure at baseline were risk factors for onset of forearm pain; women had a twofold increased risk of developing forearm pain. Self reported ergonomic workplace factors at baseline did not predict future forearm pain.

Conclusion: Intensive use of a mouse device, and to a lesser extent keyboard usage, were the main risk factors for forearm pain. The occurrence of clinical disorders was low, suggesting that computer use is not commonly associated with any severe occupational hazard to the forearm.
\end{abstract}

E the ore orearm pain has been the subject of controversy, both in the context of risks connected with exposure to repetitive motions as well as in clinical terminology.

Often forearm pain is included in broad terms such as repetitive strain injury (RSI) or cumulative trauma disorders. Others have used the terms "peritendinitis" or "intersection syndrome", implying specific pathoanatomical origins, but without rigorous clinical definitions, and in an attempt to establish surveillance case definitions in a Delphi exercise, the term "non-specific diffuse forearm pain" was proposed. The pathoanatomic mechanisms behind symptoms of forearm pain are still unknown, but local vascular abnormalities, ${ }^{3}$ thermographic changes, ${ }^{4}$ and minor nerve entrapment ${ }^{5-7}$ have been proposed as explanations for the mixture of symptoms.

Non-specific forearm pain has been reported as a common complaint among computer workers. However, inconsistent findings in epidemiological studies exploring the relation between use of computer and forearm pain have led to controversy as to whether use of computers increases the risk of arm symptoms and disorders. Furthermore, non-specific forearm pain has seldom been investigated as an isolated anatomical region, but is often included in the arm term. Punnett and Bergqvist ${ }^{8}$ concluded that intensive keyboard tasks alongside high job demands and postural stress are associated with upper extremity disorders among computer operators. In a recent prospective population based study, psychological distress, aspects of illness behaviour, and other somatic symptoms were found to predict onset of forearm pain in addition to work related mechanical factors (repetitive movements of arms), and psychosocial factors (lack of support from supervisors and colleagues).

The NUDATA study (Neck and Upper extremity Disorders Among Technical Assistants) was initiated because of public concern that computer and mouse use was a frequent cause of severe and disabling musculoskeletal disorders in the neck and upper limbs. Such cases were often presented in the media, and the possibility of a causal relation to computer work has been supported by experts on general grounds such as constrained work postures, static work load, etc, related to computer work. At the same time, however, experts were not able to pinpoint the specific factors where changes could be made to prevent the alleged adverse effects from computer work.

The aims of this study were: (1) to examine the prevalence and incidence of forearm pain alone and in combination with substantial palpation tenderness, including signs of nerve entrapment; and (2) to examine the association between forearm pain and computer work, physical work place factors, and psychosocial factors.

\section{MATERIALS AND METHODS \\ Design}

The NUDATA study is a one year follow up study examining the relation between neck and upper limb musculoskeletal symptoms and disorders, and computer use. The cohort was established in January 2000 and was recruited from the Danish Association of Professional Technicians, representing a population with a wide distribution of both mouse device usage and keyboard usage. At baseline and at one year follow up, participants completed a questionnaire; those meeting specific criteria for being a symptom case were offered a standardised clinical examination of the neck and upper extremities. All of the participants were employed at the time of inclusion in the cohort. They represent two whole occupational groups from the Danish Association of Professional Technicians, namely technical assistants (draughtsmen) and machine technicians, titles requiring a vocational education of around three years and carrying out 
Main messages

- The prevalence $(4.3 \%)$ and incidence $(1.3 \%)$ of self reported moderate to severe right forearm pain was low.

- The occurrence of clinical disorders was low, and no one developed new signs of nerve entrapment.

- Intensive use of a mouse device, and to a lesser extent keyboard usage, were the main risk factors for forearm pain.

- High job demands, time pressure, and female gender were risk factors for onset of forearm pain.

- Self reported ergonomic workplace factors did not predict future forearm pain.

technical drawing tasks, administrative and graphical tasks, and other mainly office based tasks.

The study was approved by the scientific research ethics committee.

\section{Study group}

A total of 9480 participants employed in 3527 public and private companies were invited to participate. The two occupational categories were occupied with different types of work tasks including computer aided design (CAD) work and other computer based tasks. CAD work constituted $29 \%$ of the total work hours per week (h/wk), other computer work 35\%, and non-computer work 36\%. A total of 6943 persons $(73 \%)$ completed the questionnaire at baseline, and $5658(81 \%)$ at follow up. At baseline the mean age was 41.3 years (SD 9.0) with $62.6 \%$ females and $37.4 \%$ males. On average, participants reported spending 36 hours per week (h/wk) at work, $23 \mathrm{~h} / \mathrm{wk}$ at their computer workstation, $11 \mathrm{~h} / \mathrm{wk}$ keying, and $17 \mathrm{~h} / \mathrm{wk}$ working with a mouse device.

\section{Questionnaire}

The self administered questionnaire obtained information on musculoskeletal pain and discomfort from the upper extremities, job tasks (including hours per week with or without a computer), ergonomic factors, psychosocial work characteristics, such as job demands, job control, social support and time pressure, leisure time activities, and personality characteristics (negative affectivity, type A behaviour).

\section{Exposure assessment}

\section{Work time variables}

Participants estimated their average hours per week (h/wk) doing specified work tasks during the past four weeks. Work tasks were divided by subheadings "work tasks without a computer" and "work tasks with a computer". Work without a computer was further subdivided into a list of four suggested activities and could be, for example, worksite visits and attendance at meetings. Work with a computer could be CAD work, layout/graphics, using a graphical information system (GIS), word processing, or data entry. The participants were asked to sum the estimated hours per week in all of the specified work tasks and control that the sum was equal to their average working hours during the past four weeks. In the following, the term computer time $(h / w k)$ refers to the average weekly hours working with computer during the past four weeks. Mouse time (h/wk) and keyboard time ( $h / w k$ ) were estimated by multiplying computer time with the proportion of time with active use of mouse or keyboard, respectively, as measured by questionnaire responses in six categories (almost all of computer time
Policy implications

- Computer use is not associated with any frequent severe occupational hazard with regard to clinical disorders in the forearm.

- Preventive actions should include efforts to reduce weekly usage of mouse devise and keyboard to less than 20-25 hours.

(1.0), approx. 3/4 of computer time (0.75), approx. 1/2 of computer time (0.5), approx. $1 / 4$ of computer time $(0.25)$, approx. $1 / 10$ of the time $(0.1)$, and never/almost never $(0))$.

\section{Work related physical factors}

Data concerning workstation were obtained at baseline. The participants were asked to specify the most common desk position of their keyboard and mouse device within distance intervals of $20 \mathrm{~cm}$. The questionnaire was supplied with a ruler for precise measurements. Abnormal mouse position was defined as mouse positioned more than $40 \mathrm{~cm}$ from the edge of the desk or more than $40 \mathrm{~cm}$ to the right of the shoulder. Abnormal keyboard position was defined as the centre of the keyboard positioned to the left or the right of the trunk. Forearm/wrist support during active mouse and keyboard use were reported (no support, less than half of the time, and more than half of the time). Furthermore, the participants stated whether their chair and desk could be adjusted to suit them (yes/no).

To account for other aspects of the arrangement of the workplace, a "mixed" ergonomic/psychosocial variable ("How satisfied are you with the overall arrangement of your work place?") with response alternatives very satisfied, satisfied, neither satisfied nor unsatisfied, unsatisfied, very unsatisfied, don't know, was included.

\section{Work related psychosocial factors}

Psychosocial risk factors were assessed using a standardised questionnaire developed by the Danish National Institute of Occupational Health. The same questions were asked at baseline and after one year. The questionnaire included 10 items on job demands (four on work load, three on sensory demands, and three on cognitive demands); seven items on job control (four on decision latitude and three on degree of freedom in work); and two items on social support (one on support from supervisors, and one on support from colleagues). Responses were categorised into five alternatives (always, often, sometimes, seldom, never/almost never). Each item was dichotomised between "often" and "sometimes" and given a raw score of 1 or 0 , summed to form three scales: job demand, job control, social support. In the analyses, the scales were finally dichotomised into high and low scale values. High scale values indicate a high level of job demands, a low level of job control, and a low level of social support. Cronbach's alpha was 0.79 for the 10 items demand scale and 0.75 for the 7 items control scale. The Spearman coefficient of correlation between the two items on social support was 0.49 . If less than half of the items in a scale were missing, the missing values were estimated as the average of the other items. If half or more than half of the items in the scale were missing, the scale value was set to missing.

\section{Personal characteristics}

Data on several personal characteristics, including age and gender, were collected. Body mass index was calculated from self reported weight and height and categorised into low, normal, and high $\left(<19 \mathrm{~kg} / \mathrm{m}^{2}, 19-26 \mathrm{~kg} / \mathrm{m}^{2},>27 \mathrm{~kg} / \mathrm{m}^{2}\right)$. 
Table 1 Definition, symptoms, and signs of syndromes of the forearm

\begin{tabular}{|c|c|c|}
\hline & \multicolumn{2}{|l|}{ Case definition } \\
\hline & Self reported symptoms & Clinical examination \\
\hline \multicolumn{3}{|l|}{ At baseline } \\
\hline \multicolumn{3}{|l|}{ Symptom cases } \\
\hline Present symptom case & $\begin{array}{l}\text { At least moderate pain in the forearm within the } \\
\text { past } 7 \text { days. }\end{array}$ & \\
\hline Chronic symptom case & $\begin{array}{l}\text { Quite a lot of pain/discomfort and pain/discomfort } \\
\text { more than } 30 \text { days within the past } 12 \text { months. }\end{array}$ & \\
\hline \multicolumn{3}{|c|}{. } \\
\hline Clinical forearm case & $\begin{array}{l}\text { At least moderate pain in the forearm within the past } \\
7 \text { days combined with quite a lot of pain/discomfort } \\
\text { during the past } 12 \text { months. }\end{array}$ & $\begin{array}{l}\text { Moderate/severe palpation tenderness (graded } 2 \text { or } 3 \text { ) in } \\
\text { the proximal aspect of the forearm. }\end{array}$ \\
\hline Supinator syndrome & $\begin{array}{l}\text { At least moderate pain in the forearm within the past } \\
7 \text { days combined with quite a lot of pain/discomfort } \\
\text { during the past } 12 \text { months. }\end{array}$ & $\begin{array}{l}\text { Substantial pressure palpation tenderness (grade } 2 \text { or } 3 \text { ) } \\
\text { over the fibrous arch at the origin of the supinator muscle } \\
\text { (the arcade of Frohse). Furthermore, resisted supination of } \\
\text { the forearm and/or resisted extension of the middle finger } \\
\text { should produce pain in the same area. }\end{array}$ \\
\hline Pronator teres case & $\begin{array}{l}\text { At least moderate pain in the forearm within the past } \\
7 \text { days combined with quite a lot of pain/discomfort } \\
\text { during the past } 12 \text { months. }\end{array}$ & $\begin{array}{l}\text { Substantial pressure palpation tenderness (grade } 2 \text { or } 3 \text { ) } \\
\text { on the volar side of the proximal forearm. Furthermore, } \\
\text { resisted pronation of the forearm and/or resisted flexion of } \\
\text { the middle finger should produce pain in the pronator teres } \\
\text { area or paresthesias in dig } 1-3 .^{15}\end{array}$ \\
\hline \multicolumn{3}{|r|}{ 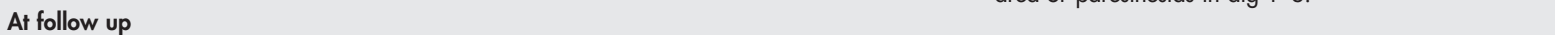 } \\
\hline \multicolumn{3}{|l|}{ Symptom cases } \\
\hline Incident symptom case & $\begin{array}{l}\text { At baseline: None or less than moderate pain in the } \\
\text { forearm within the past } 7 \text { days combined with less } \\
\text { than "some" pain/discomfort during the past } \\
12 \text { months; and } \\
\text { At follow up: At least moderate to severe pain in } \\
\text { the forearm within the past } 7 \text { days combined with } \\
\text { quite a lot of pain/discomfort during the past } \\
12 \text { months. }\end{array}$ & \\
\hline \multicolumn{3}{|c|}{ 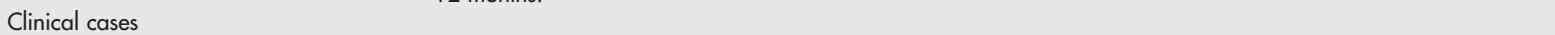 } \\
\hline Incident clinical forearm case & $\begin{array}{l}\text { Same as incident symptom case combined with clinical } \\
\text { findings. }\end{array}$ & $\begin{array}{l}\text { Moderate/severe palpation tenderness (graded } 2 \text { or } 3 \text { ) in } \\
\text { the proximal aspect of the forearm. }\end{array}$ \\
\hline
\end{tabular}

Leisure time activity was categorised into low physical activity (almost none or light physical activity $<2 \mathrm{~h} / \mathrm{wk}$ or light activity for $2-4 \mathrm{~h} / \mathrm{wk}$ ), and high physical activity (light physical activity $>4 \mathrm{~h} /$ wk or 2-4 hours with hard physical activity or hard physical activity for $>4 \mathrm{~h} / \mathrm{wk}$ ). Type A behaviour ("Do you tend to be competitive, jealous, ambitious, and somewhat impatient?") and negative affectivity ("Do you tend to be worried, nervous, or somewhat pessimistic?)" was measured by two global questions with seven response alternatives (not at all, very little, little, some, quite a lot, much, very much). Responses were dichotomised between "quite a lot" and "much". Poor social network was measured only at baseline by one question: "If you have problems, is it possible to obtain the necessary support from family or friends?". Responses with six alternatives (always, nearly always, usually, often, sometimes, seldom/never) were dichotomised between "often" and "sometimes". Furthermore, participants were asked whether they suffered from specific medical conditions, which are potentially associated with musculoskeletal or neurological impairment (for example, arthritis, osteoarthritis, neuritis, inflammation of the connective tissue, paralysis of part of the body, stroke, diabetes, thyroid illness, fibromyalgia).

\section{Outcome measures}

Information concerning musculoskeletal symptoms from the neck, shoulders, elbows, forearms, and wrists/hands (nine regions) were obtained. Forearm pain within the past seven days was assessed on a nominal scale with eight pain categories (no pain, very little pain, little pain, little to moderate pain, moderate pain, moderate to severe pain, severe pain, and very severe pain). Level of discomfort due to pain (very little, little, somewhat; quite a lot; much; very much), and duration of pain ( $1-7$ days, 8-30 days, 31-90 days, more than 90 days but not every day, every day) within the past 12 months were recorded.

Participants who at baseline indicated at least moderate pain in the forearm within the past seven days were offered a clinical examination at their local department of occupational medicine. Participants were not eligible for examination if they had had an operation on the forearm, if pain was caused by trauma, or if they suffered from the aforementioned medical conditions.

A total of 275 symptom forearm cases were invited and $85 \%(\mathrm{n}=235)$ accepted an invitation for medical examination. Two independent clinical examinations were performed. In one examination the physician was blind to the answers from the questionnaire and examined all the nine target regions irrespective of regional case status. In the other, the physician was informed about case status and examined the case region and the adjacent region(s), and a structured interview was performed concerning onset of symptoms, precise localisation, present pain status, medication, sick leave, and medical treatment for the pain.

The forearm region was defined proximally as a transversal plane $5 \mathrm{~cm}$ below the olecranon and distally as a transversal plane just proximally to the processus styloideus ulnae.'

The dorsal and volar side of the forearm were subdivided into four regions with respect to the lateral/medial and proximal/distal aspect of the arm, and the surfaces of the regions were systematically palpated. Palpation tenderness and clinical tests for supinator and pronator syndrome were recorded. Palpation was carried out with approximately $4 \mathrm{~kg}$ pressure.

Palpation tenderness was scored on a $0-3$ scale $(0$, non; 1 , mild without withdrawal; 2, moderate with withdrawal; 3 , severe with jump sign). Only scores 2 and 3 were considered as clinically relevant tenderness. 
Study participants were classified according to their self reported symptoms and the results of the clinical examination. Table 1 provides specific case definitions.

The physical function of participants was measured at the clinical examination by the DASH (Disabilities of the Arm, Shoulder, and Hand) outcome measure, which ranges from 0 to 100 , where 100 represents maximum disability. ${ }^{10}$

\section{Statistical analyses}

Baseline analyses used logistic regression analyses and all risk factors were kept in the models irrespective of level of significance. Mouse device use and keyboard use were analysed by assigning dummy variables for weekly usage time, split into $0-2.4,2.5-4,5-9,10-14,15-19,20-24,25-29$, and $\geqslant 30$ hours per week. Prior to this analysis a generalised additive model was used to test for non-linearity in the relation between continuous weekly usage in hours and forearm pain. There was no gain from including terms other than the linear, and in particular we could not obtain any threshold values for time with mouse device or keyboard use.

In the analysis with follow up data the risk of developing moderate to severe forearm pain was examined by logistic regression among participants free of moderate to severe forearm pain at baseline. Because of a shortage of incident cases $(n=67)$ we used another strategy for analysis in the follow up. Intensity of mouse device use was divided into four groups (0-9 hours, 10-19 hours, 20-29 hours, and $\geqslant 30$ hours per week). Keyboard usage was divided into 0-4 hours, 5-9 hours, 10-14 hours, and $\geqslant 15$ hours per week. The other risk factors were grouped into physical risk factors, psychosocial risk factors, and personal risk factors, and we then performed stepwise analyses by forcing mouse and keyboard use into three models including each of the groups of potential confounders, and eliminating all factors with $\mathrm{p}$ values greater than 0.10 . The final model then included mouse and keyboard time (each with four dummy variables), two psychosocial factors (high job demands and time pressure), and the personal factors negative affectivity, age, and gender. To check for colinearity we calculated the correlation coefficient between the risk factors; they were always lower than 0.25 . Introducing an interaction term between mouse and keyboard usage did not enhance the model significantly. We further introduced the variable "computer time (h/wk)" in the final model to test whether computer use per se was a risk factor for the onset of forearm pain $(\mathrm{p}=0.63)$.

\section{RESULTS}

\section{Recruitment}

At baseline 3034 participants (43.7\%) answered immediately, and two further reminders to non-responders (the second with a new questionnaire) were completed by 2056 (29.6\%) and $1853(26.7 \%)$, giving an overall participation of 6943 $(73.2 \%)$. There were no differences in age or time related exposure variables in relation to response time to the questionnaire, but the prevalence of present forearm pain decreased from $5.6 \%$ among immediate responders to $3.7 \%$ in the second wave and $2.9 \%$ in the third wave.

Participants at baseline who did not participate in the follow up $(\mathrm{n}=1285)$ did not differ from those who did with respect to the prevalence of symptoms or with respect to computer time, mouse time, or keyboard time. They differed significantly with respect to gender and age. There were more young males in the non-responder group.

\section{Prevalence of forearm cases}

Table 2 shows descriptive data of the total population. The prevalence of reported symptom cases was 4.3\% (296 participants) in the right forearm and 1\% (70 participants) in the left forearm (fig 1). Among the right symptom cases, 87 complained of moderate to severe pain, 41 of severe pain, and five of very severe pain during the past seven days. Fifty three per cent (156) of right forearm cases were also right elbow cases, and 58\% (173) were also right wrist/hand cases. Among the participants with moderate to severe right side forearm complaints, $97 \%$ also reported that the pain had bothered them quite a lot or more during the last year, and $77 \%$ reported having had pain for more than 30 days.

In the blinded examination, 18 met our criteria for being a clinical case ( 16 on the right forearm and two on the left) and 12 had signs of possible nerve entrapment on the right side (nine with signs of supinator syndrome and three with signs of pronator teres syndrome). Seven clinical cases had signs of nerve entrapment, too. The non-blinded examination found 27 clinical cases. The agreement between the blinded and non-blinded examination regarding forearm cases was low (kappa 0.32, SE 0.01).

The severity of physical disability measured by the DASH was mild to moderate, with mean scores of 22.5 among present symptom cases, 23.8 among chronic symptom cases, and 39.3 among clinical cases. ${ }^{11}$

\section{Incidence of forearm cases}

One year incidence of self reported symptom cases was 67 (1.3\%) in the right forearm and $20(0.4 \%)$ in the left forearm. Among the right symptom cases, only 27 had reported no symptoms at all during the past 12 months prior to baseline. Around half of the participants who reported onset of forearm pain at follow up also reported onset of elbow and hand pain. Six met our criteria for being a clinical case. No one developed new signs of nerve entrapment.

\section{Physical risk factors}

At baseline the there was a somewhat irregular exposureresponse relation between mouse use and present symptom case (table 3 ). The associations became significant for 59 hours of weekly usage compared with weekly usage for 02.4 hours per week (OR 2.7, 95\% CI 1.3 to 5.6), and with further increase in mouse the odds ratios were as follows: 1014 hours per week (OR 1.9; 95\% CI 0.9 to 4.0 ), 15-19 hours per week (OR $4.1 ; 95 \%$ CI 2.0 to 8.2 ), 20-24 hours per week (OR 3.3; 95\% CI 1.6 to 7.0 ), 25-29 hours per week (OR 7.5; $95 \%$ CI 3.4 to 16), and for more than 30 hours (OR 7.3; 95\% CI 3.1 to 17). The risk estimates were quite similar for the two different outcomes measures "present symptom case" and "chronic symptom case". Keyboard use for more than 15 hours per week revealed a slightly increased risk of forearm pain, although this was not significant at the $5 \%$ level. Shortage of clinical cases restricted possibilities for carrying out full analyses, but the OR of being a clinical case were 8.2 (CI 1.5 to 43.5 ) among participants using a mouse device for more than 30 hours per week in a logistic model, which included mouse time, keyboard time, gender, and age.

The risk of onset of new forearm pain was associated with mouse time use above 10 hours per week, and those with mouse usage for more than 30 hours had an increased OR of 8.4 (CI 2.5 to 28.9 ) (table 4). A slightly increased risk of new forearm pain was found for keyboard usage more than 15 hours per week with an increased OR of 2.6 (CI 0.9 to 7.3 ). Self reported ergonomic factors at baseline, such as lack of arm/wrist support, abnormal keyboard/mouse position, or lack of possibility to adjust table or chair had no effect on the onset of forearm pain. At baseline, we found an association between the prevalence of forearm pain and overall dissatisfaction with the way the workplace was physically arranged, but this effect could not be identified in the follow up analyses. 
Table 2 Prevalence and incidence of right side symptom forearm cases and clinical forearm case characteristics*

\begin{tabular}{|c|c|c|c|c|c|c|c|c|c|}
\hline & \multirow[b]{2}{*}{ Categories } & \multirow{2}{*}{$\begin{array}{l}\begin{array}{l}\text { At } \\
\text { baseline }\end{array} \\
n\end{array}$} & \multicolumn{2}{|c|}{$\begin{array}{l}\text { Symptom forearm } \\
\text { cases at baseline } \\
n=296\end{array}$} & \multicolumn{2}{|c|}{$\begin{array}{l}\text { Clinical forearm } \\
\text { cases at baseline } \dagger \\
n=21\end{array}$} & \multirow{2}{*}{$\begin{array}{l}\text { At } 1 \text { year } \\
\text { follow up } \\
n\end{array}$} & \multicolumn{2}{|c|}{$\begin{array}{l}\text { Symptom forearm } \\
\text { cases at follow up } \\
n=67\end{array}$} \\
\hline & & & $\mathbf{n}$ & $\%$ & $\mathbf{n}$ & $\%$ & & $\mathbf{n}$ & $\%$ \\
\hline \multicolumn{10}{|l|}{ Physical workplace factors } \\
\hline Hours per week with mouse in & $0-2.4$ & 1552 & 55 & 3.5 & 3 & 0.2 & 1279 & 13 & 1.0 \\
\hline \multirow[t]{7}{*}{ right hand } & $2.5-4$ & 474 & 11 & 2.3 & 1 & 0.2 & 380 & 2 & 0.5 \\
\hline & $5-9$ & 845 & 32 & 3.8 & 2 & 0.2 & 676 & 7 & 1.0 \\
\hline & $10-14$ & 1200 & 33 & 2.8 & 1 & 0.1 & 980 & 12 & 1.2 \\
\hline & $15-19$ & 1086 & 66 & 6.1 & 5 & 0.5 & 877 & 11 & 1.3 \\
\hline & $20-24$ & 861 & 36 & 4.2 & 5 & 0.6 & 706 & 9 & 1.3 \\
\hline & $25-30$ & 372 & 32 & 8.6 & 0 & 0.0 & 313 & 2 & 0.6 \\
\hline & $>30$ & 292 & 24 & 8.2 & 4 & 1.4 & 248 & 8 & 3.2 \\
\hline Arm/wrist support during use & No & 1652 & 67 & 4.1 & 3 & 0.2 & 1350 & 15 & 1.1 \\
\hline \multirow{2}{*}{ of mouse } & $0-50 \%$ of time & 615 & 26 & 4.2 & 0 & 0.0 & 484 & 8 & 1.7 \\
\hline & $50-100 \%$ of time & 4296 & 193 & 4.5 & 17 & 0.4 & 3530 & 39 & 1.1 \\
\hline \multirow[t]{2}{*}{ Abnormal mouse position } & No & 6424 & 283 & 4.4 & 21 & 0.3 & 5250 & 60 & 1.1 \\
\hline & Yes & 519 & 13 & 2.5 & 0 & 0.0 & 408 & 7 & 1.7 \\
\hline Keyboard time in hours per week & $0-2.4$ & 663 & 24 & 3.6 & 2 & 0.3 & 529 & 9 & 1.7 \\
\hline & $2.5-4$ & 1217 & 63 & 5.2 & 4 & 0.3 & 987 & 9 & 1.0 \\
\hline & $5-9$ & 2291 & 85 & 3.7 & 6 & 0.3 & 1871 & 20 & 1.1 \\
\hline & $10-14$ & 1607 & 61 & 3.8 & 6 & 0.4 & 1342 & 14 & 1.0 \\
\hline & $15-19$ & 759 & 45 & 5.9 & 3 & 0.4 & 604 & 11 & 1.8 \\
\hline & $20-24$ & 191 & 9 & 4.7 & 0 & 0.0 & 166 & 2 & 1.2 \\
\hline & $25-30$ & 69 & 3 & 4.3 & 0 & 0.0 & 54 & 0 & 0.0 \\
\hline & $>30$ & 37 & 2 & 5.4 & 0 & 0.0 & 30 & 1 & 3.3 \\
\hline Arm/wrist support during use of & No & 2507 & 102 & 4.1 & 4 & 0.2 & 2052 & 28 & 1.4 \\
\hline keyboard & $0-50 \%$ of time & 1400 & 74 & 5.3 & 6 & 0.4 & 1133 & 11 & 1.0 \\
\hline & $50-100 \%$ of time & 2870 & 116 & 4.0 & 11 & 0.4 & 2359 & 26 & 1.1 \\
\hline Abnormal keyboard position & No & 5818 & 246 & 4.2 & 21 & 0.4 & 4768 & 56 & 1.2 \\
\hline & Yes & 911 & 46 & 5.0 & 0 & 0.0 & 735 & 10 & 1.4 \\
\hline Work chair adjusted & No & 223 & 14 & 6.3 & 0 & 0.0 & 181 & 1 & 0.6 \\
\hline & Yes & 6671 & 282 & 4.2 & 1 & 0.01 & 5448 & 66 & 1.2 \\
\hline Work desk adjusted & No & 1692 & 59 & 3.5 & 3 & 0.2 & 1349 & 11 & 0.8 \\
\hline & Yes & 5178 & 233 & 4.5 & 18 & 0.3 & 4264 & 56 & 1.3 \\
\hline Satisfied with workplace design & No & 920 & 67 & 7.3 & 2 & 0.2 & 735 & 8 & 1.1 \\
\hline & Yes & 5981 & 228 & 3.8 & 19 & 0.3 & 4898 & 59 & 1.2 \\
\hline Psychosocial workplace factors & & & & & & & & & \\
\hline High demands & No & 4094 & 161 & 3.9 & 14 & 0.3 & 3407 & 33 & 1.0 \\
\hline & Yes & 2798 & 134 & 4.8 & 7 & 0.3 & 2213 & 32 & 1.5 \\
\hline Low control & No & 4661 & 172 & 3.7 & 12 & 0.3 & 3776 & 41 & 1.1 \\
\hline & Yes & 2223 & 124 & 5.6 & 9 & 0.4 & 1845 & 24 & 1.3 \\
\hline Low social support & No & 4086 & 140 & 3.4 & 4 & 0.1 & 3339 & 35 & 1.0 \\
\hline & Yes & 2755 & 149 & 5.4 & 15 & 0.5 & 2238 & 29 & 1.3 \\
\hline Strain & No & 6095 & 246 & 4.0 & 18 & 0.3 & 4977 & 55 & 1.1 \\
\hline & Yes & 781 & 49 & 6.3 & 3 & 0.4 & 628 & 10 & 1.6 \\
\hline Time pressure & No & 5158 & 190 & 3.7 & 17 & 0.3 & 4231 & 44 & 1.0 \\
\hline & Yes & 1741 & 106 & 6.1 & 4 & 0.2 & 1400 & 22 & 1.6 \\
\hline Personal characteristics & & & & & & & & & \\
\hline Negative affectivity & No & 5772 & 250 & 4.3 & 19 & 0.3 & 4714 & 52 & 1.1 \\
\hline & Yes & 935 & 39 & 4.2 & 2 & 0.2 & 765 & 13 & 1.7 \\
\hline Type A behaviour & No & 5725 & 234 & 4.1 & 19 & 0.3 & 4713 & 52 & 1.1 \\
\hline & Yes & 916 & 52 & 5.7 & 2 & 0.2 & 706 & 8 & 1.1 \\
\hline Age (years) & $20-29$ & 654 & 33 & 5.0 & 1 & 0.2 & 478 & 7 & 1.5 \\
\hline & $30-39$ & 2592 & 102 & 3.9 & 10 & 0.4 & 2025 & 15 & 0.7 \\
\hline & $40-49$ & 2201 & 103 & 4.7 & 6 & 0.3 & 1858 & 20 & 1.1 \\
\hline & $50-59$ & 1397 & 58 & 4.2 & 4 & 0.3 & 1215 & 25 & 1.9 \\
\hline & $60-66$ & 99 & 0 & 0.0 & 0 & 0.0 & 82 & 0 & 0.0 \\
\hline Gender & Male & 2596 & 64 & 2.5 & 3 & 0.1 & 2042 & 16 & 0.8 \\
\hline & Female & 4347 & 232 & 5.3 & 18 & 0.4 & 3614 & 51 & 1.4 \\
\hline BMI & Low & 216 & 6 & 2.8 & 0 & 0.0 & 180 & 2 & 1.1 \\
\hline & Normal & 6231 & 264 & 4.2 & 17 & 0.3 & 5077 & 59 & 1.2 \\
\hline & High & 371 & 20 & 5.4 & 1 & 0.3 & 308 & 3 & 1.0 \\
\hline Poor social network & No & 6189 & 264 & 4.3 & 17 & 0.3 & 5041 & 58 & 1.2 \\
\hline & Yes & 590 & 28 & 4.7 & 4 & 0.7 & 492 & 7 & 1.4 \\
\hline Leisure time physical activity & Low & 3938 & 183 & 4.6 & 13 & 0.3 & 3218 & 42 & 1.3 \\
\hline & High & 2930 & 113 & 3.9 & 8 & 0.3 & 2369 & 23 & 1.0 \\
\hline Chronic diseases & No & 6506 & 273 & 4.2 & 21 & 0.3 & 5282 & 60 & 1.1 \\
\hline & Yes & 437 & 23 & 5.3 & 0 & 0.0 & 376 & 7 & 1.9 \\
\hline Pain started after forearm & No & 6755 & 286 & 4.2 & 20 & 0.3 & 5629 & 66 & 1.2 \\
\hline accident & Yes & 188 & 10 & 5.3 & 0 & 0.0 & 29 & 1 & 3.4 \\
\hline
\end{tabular}




$\begin{aligned} & \text { Forearm cases } \\ & \text { (right side) }\end{aligned}$
Baseline participants
Completed follow
up questionnaire?

Figure 1 Flow chart of right side forearm cases during baseline and one year follow up.

\section{Psychosocial and individual risk factors}

Onset of forearm pain was related to high job demands and time pressure, and at baseline there was a minor effect of lack of support from supervisors and colleagues, but this was not confirmed at follow up (table 4). Other psychosocial risk factors were not significantly associated with forearm pain.

Women had a twofold increased risk of developing forearm pain, whereas age had no effect on the onset of pain.

The effect of introducing time with computer into the final model did not contribute to the model $(p=0.70)$, which indicates that the effect of time variables is an effect from the actual use of mouse device or keyboard, and not an unspecified effect of computer use per se.

\section{DISCUSSION}

The prevalence and incidence of right forearm pain was independently related to intensive use of mouse device and to a lesser extent to keyboard usage, female gender, high job demands, and time pressure at work. The occurrence of clinical disorders was low, and computer use is not associated with any frequent severe occupational hazard with regard to clinical disorders in the forearm.

The NUDATA study was designed as a follow up study of a large cohort of computer users with the intention of obtaining a broad distribution of both mouse device use and keyboard use. It was a requirement that there would be enough subjects to enable relevant analyses of both symptoms and clinical diagnoses. The low occurrence of moderate to severe pain in combination with our clinical criteria revealed only a few clinical cases in the forearm: $4 \%$ reported prevalent forearm symptoms and only $0.3 \%$ met our criteria for clinical findings. The only other follow up study with clinical assessment of computer users, ${ }^{12}$ found a prevalence of hand/arm symptoms at baseline of $4 \%$, corresponding to that found in our study, but they found that $64 \%$ of these met their criteria for hand-arm clinical disorders. Most of these disorders were tendon related, but clinical criteria also involved findings such as point tenderness, which could also be muscle related. In the present study $5 \%$ of the participants with moderate to severe pain in the forearm had clinical signs of lateral epicondylitis, and only $1 \%$ had signs of DeQuervain. Thus specific disorders in the elbow and wrist can only explain a minor proportion of the unspecific forearm pain. However, there are great discrepancies between the two studies in the incidence rates, but selection mode and criteria for being examined vary to a degree that makes comparisons difficult.

Signs of supinator syndrome and pronator teres syndrome were very seldom seen in this study. Only $0.2 \%$ had clinical signs of these nerve entrapments at baseline, and no new cases appeared during the follow up period. We are not aware of other studies, which have attempted to investigate the prevalence of specific nerve entrapments in the forearm among computer users.

A limitation in our baseline study was a modest participation rate of $73.2 \%$. The decreasing prevalence of pain in relation to response time for answering the questionnaire points towards a still lower prevalence of pain among nonresponders, and the prevalence estimates are therefore probably slightly overestimated in the baseline analyses. At follow up, there were no differences in either pain status or time related exposure variables (at baseline) among those who completed the follow up and those who did not.

The threshold analyses did not indicate any specific threshold for mouse time and keyboard time, as none of the threshold models were significantly better than a model fitting a linear effect. The linear effect was significant for mouse time as well as keyboard time, indicating that an effect was present from just a few hours use of mouse or keyboard per week. In our opinion however, it is not very plausible that this finding reflects a true physical effect of mouse or keyboard use. If pain in the forearm was caused by repetitive motions of the hand and forearm, one would, from a biological standpoint, expect a threshold level, below which no effect on the outcome is seen up to a certain period of weekly usage, and then an increasing effect on the outcome above this threshold level. As all possible confounders in the study were included in the analyses, we cannot explain why mouse and keyboard time seemed to have a linear effect starting from zero hours per week. Maybe this is a true representation, but reporting bias could be another possible explanation, even though we introduced this study to participants as a study of "work environment and health". Recent use of the new terms "mouse injury" and "mouse arm" could induce a tendency to report symptoms in accordance with being a computer worker and using a mouse device. This may be a plausible explanation for prevalence values at baseline, but at first sight, it does not explain incidence levels. However, it must be pointed out that our incident cases were not "pure" incident cases; incident cases were allowed to have had mild symptoms at baseline, since "pure" incident cases were too few (27 of 67 incident forearm cases) for the intended analyses. The validity of self reported mouse and keyboard times may also be questioned. In a recent experimental study, self reported mouse and keyboard times were shown to be $2-3$ times lower than objectively 
Table 3 Unadjusted and adjusted odds ratios (OR) for present and chronic symptom cases in relation to physical and psychosocial workplace factors, and personal characteristics

\begin{tabular}{|c|c|c|c|c|}
\hline & \multicolumn{2}{|c|}{ Present symptom case } & \multicolumn{2}{|c|}{ Chronic symptom case } \\
\hline & Crude OR & Adjusted OR (95\% Cl) & Crude OR & Adjusted OR (95\% Cl) \\
\hline \multicolumn{5}{|l|}{ Physical workplace factors } \\
\hline \multicolumn{5}{|l|}{ Hours per week with mouse in right hand } \\
\hline $0-2.4$ & 1 & 1 & 1 & 1 \\
\hline $2.5-4$ & 1.6 & $1.5(0.6$ to 3.6$)$ & 1.5 & $1.2(0.5$ to 2.8$)$ \\
\hline $5-9$ & 2.5 & $2.7(1.3$ to 5.6$)$ & 2.6 & $2.7(1.4$ to 5.1$)$ \\
\hline $10-14$ & 1.8 & $1.9(0.9$ to 4.0$)$ & 1.9 & $2.2(1.1$ to 4.2$)$ \\
\hline $15-19$ & 4.2 & $4.1(2.0$ to 8.2$)$ & 3.6 & $3.8(2.0$ to 7.1$)$ \\
\hline $20-24$ & 2.9 & $3.3(1.6$ to 7.0$)$ & 3.0 & $2.9(1.5$ to 5.7$)$ \\
\hline $25-29$ & 6.2 & $7.5(3.4$ to 16$)$ & 4.9 & $5.8(2.9$ to 12$)$ \\
\hline$\geqslant 30$ & 5.9 & 7.3 (3.1 to 17$)$ & 6.0 & 6.3 (2.9 to 14$)$ \\
\hline No arm support (mouse) & 1 & 1 & 1 & 1 \\
\hline Arm support (mouse) < $50 \%$ time & 1.0 & $1.1(0.6$ to 2.0$))$ & 1.0 & $1.2(0.7$ to 2.0$)$ \\
\hline Arm support (mouse) $\geqslant 50 \%$ time & 0.7 & $1.1(0.7$ to 1.8$)$ & 0.7 & $1.2(0.8$ to 1.9$)$ \\
\hline Abnormal mouse position & 0.7 & $0.6(0.3$ to 1.1$)$ & 0.6 & $0.6(0.4$ to 1.1$)$ \\
\hline \multicolumn{5}{|l|}{ Keyboard time in hours per week } \\
\hline $0-2.4$ & 1 & 1 & 1 & 1 \\
\hline $2.5-4$ & 1.5 & $1.1(0.6$ to 2.2$)$ & 1.1 & $0.9(0.5$ to 1.6$)$ \\
\hline $5-9$ & 1.0 & $1.1(0.6$ to 2.1$)$ & 0.8 & $1.0(0.6$ to 1.6$)$ \\
\hline $10-14$ & 1.1 & $1.6(0.8$ to 3.1$)$ & 0.6 & $0.8(0.5$ to 1.4$)$ \\
\hline $15-19$ & 1.6 & $1.8(0.9$ to 3.7$)$ & 1.1 & $1.3(0.7$ to 2.3$)$ \\
\hline$\geqslant 20$ & 1.5 & $2.9(1.2$ to 7.1$)$ & 1.0 & $2.1(0.9$ to 4.5$)$ \\
\hline No arm support (keyboard) & 1 & 1 & 1 & 1 \\
\hline Arm support (keyboard) $<50 \%$ time & 0.7 & $1.5(1.1$ to 2.1$)$ & 0.9 & $1.1(0.8$ to 1.6$)$ \\
\hline Arm support (keyboard) $\geqslant 50 \%$ time & 1.2 & $1.0(0.7$ to 1.3$)$ & 1.2 & $0.8(0.6$ to 1.1$)$ \\
\hline Abnormal keyboard position & 1.4 & $1.3(0.9$ to 1.8$)$ & 1.5 & $1.6(1.2$ to 2.3$)$ \\
\hline Work chair not adjusted & 1.5 & $1.8(0.9$ to 3.6$)$ & 1.2 & $1.5(0.8$ to 2.8$)$ \\
\hline Work table not adjusted & 0.8 & $0.7(0.4$ to 1.0$)$ & 0.8 & $0.7(0.5$ to 1.0$)$ \\
\hline Not satisfied with workplace design & 1.9 & $2.0(1.3$ to 3.0$)$ & 1.8 & $1.8(1.2$ to 2.6$)$ \\
\hline \multicolumn{5}{|l|}{ Psychosocial workplace factors } \\
\hline High demands & 1.1 & $1.0(0.7$ to 1.4$)$ & 1.2 & $1.1(0.9$ to 1.5$)$ \\
\hline Low control & 1.6 & $1.1(0.8$ to 1.5$)$ & 1.4 & $1.1(0.8$ to 1.5$)$ \\
\hline Low social support & 1.6 & $1.3(0.9$ to 1.7$)$ & 1.3 & $1.2(1.0$ to 1.6$)$ \\
\hline Time pressure & 1.6 & $1.4(1.0$ to 2.0$)$ & 1.5 & $1.3(1.0$ to 1.7$)$ \\
\hline \multicolumn{5}{|l|}{ Personal characteristics } \\
\hline Negative affectivity & 1.1 & $0.9(0.6$ to 1.4$)$ & 1.4 & $1.3(1.0$ to 1.9$)$ \\
\hline Type A behaviour & 1.3 & 1.5 (1.0 to 2.2$)$ & 1.4 & $1.4(1.0$ to 2.0$)$ \\
\hline Age (10 years increment) & 1.0 & $1.1(0.9$ to 1.3$)$ & 1.1 & $1.1(0.9$ to 1.3$)$ \\
\hline Female gender & 2.3 & $2.2(1.5$ to 3.1$)$ & 2.3 & $2.0(1.4$ to 2.7$)$ \\
\hline $\mathrm{BMI}<19 \mathrm{~kg} / \mathrm{m}^{2}$ & 0.8 & $0.7(0.3$ to 1.7$)$ & 0.7 & $0.7(0.3$ to 1.5$)$ \\
\hline$B M I \geqslant 27 \mathrm{~kg} / \mathrm{m}^{2}$ & 1.4 & $1.2(0.7$ to 2.0$)$ & 1.2 & $0.9(0.5$ to 1.5$)$ \\
\hline Poor social network & 1.3 & $1.1(0.7$ to 1.7$)$ & 1.3 & $1.2(0.8$ to 1.8$)$ \\
\hline High physical activity & 0.8 & 0.9 (0.7 to 1.2$)$ & 0.9 & $1.1(0.8$ to 1.4$)$ \\
\hline Medical disorder & 1.4 & $1.7(1.1$ to 2.8$)$ & 1.3 & $1.6(1.0$ to 2.5$)$ \\
\hline Pain started after accident & 1.5 & $1.5(0.7$ to 3.2$)$ & 0.7 & 0.7 (0.3 to 1.8 ) \\
\hline
\end{tabular}

measured. ${ }^{13}$ However, the rank correlations between self reported times and objective times were 0.71 and 0.78 for mouse and keyboard times, respectively, when self reports were made at the end of the same day as the measurements were made. In real life, including retrospective assessment over longer periods, for example, four weeks, as used in the present study, these correlations may well be lower. However, if the misclassification is independent of the true exposure level and the outcome studied, the findings of an exposureresponse relation would in principle be underestimated. If not, false positive or false negative exposure-response patterns may result.

In the study of Homan and Armstrong, ${ }^{13}$ self reported keyboard times were overestimated to a higher degree at low objective keyboard times than at high keyboard times. If this pattern of overestimation is also present in our study for mouse and keyboard times, one would underestimate the magnitude of a true exposure-response relation.

In the incidence analyses, only mouse time above 30 hours per week was significant in all the models (table 4). If we consider the associations in the baseline cross section to be partly skewed by reporting bias, and if we should epitomise the results at baseline, at follow up, and the clinical findings, we trust that self reported mouse device usage above 2530 hours per week implies a risk for forearm pain, and that self reported keyboard time over approximately 20 hours per week also implies a small increased risk for forearm pain. A population based study of forearm pain has shown that besides work related factors, the onset of forearm pain is associated with other somatic symptoms, illness behaviour, and psychological distress. ${ }^{1}$ In our study, forearm pain was also strongly associated with other somatic symptoms, and the multifactorial nature of forearm pain warrants against a term like "mouse arm". We found no effect of the ergonomic, postural risk factors on either prevalence or incidence of forearm pain, but at baseline we found an effect of overall dissatisfaction with the way the workplace was arranged. This effect disappeared in the follow up analyses, and it probably reflects the fact that reports of job satisfaction generally are strongly related to pain experience in cross sectional studies. We found no effect on the onset of forearm pain from lack of wrist/forearm support, keyboard or mouse position, or a lack of possibility for adjusting desk or chair. All these variables were self reported, and we did not include measurements of angles, as Marcus and colleagues ${ }^{14}$ have done. In that study only weak associations were found 
Table 4 Odds ratios (OR) for becoming a new symptom forearm case during follow up for those with no or mild symptoms at baseline

\begin{tabular}{|c|c|c|c|c|}
\hline & \multicolumn{4}{|l|}{ OR $(95 \% \mathrm{Cl})$} \\
\hline & $\begin{array}{l}\text { Model } \mathrm{I}^{*} \\
\mathrm{n}=\mathbf{4 3 0 5}\end{array}$ & $\begin{array}{l}\text { Model IIt } \\
n=4408\end{array}$ & $\begin{array}{l}\text { Model III } \\
\mathrm{n}=4190\end{array}$ & $\begin{array}{l}\text { Model IV } \S \\
n=4340 \text { (64 cases }\end{array}$ \\
\hline \multicolumn{5}{|l|}{ Physical workplace factors } \\
\hline \multicolumn{5}{|l|}{ Hours per week with mouse in right hand } \\
\hline 0-9 & 1 & 1 & 1 & 1 \\
\hline $10-19$ & $1.8(0.9$ to 3.9$)$ & $2.2(1.0$ to 4.6$)$ & $1.9(0.9$ to 4.1$)$ & $2.2(1.0$ to 4.7$)$ \\
\hline $20-29$ & $1.8(0.7$ to 4.6$)$ & $2.5(1.0$ to 6.1$)$ & $2.2(0.9$ to 5.7$)$ & 2.6 (1.0 to 6.6$)$ \\
\hline$\geqslant 30$ & 6.8 (2.1 to 23$)$ & 8.8 (2.6 to 29 ) & $6.8(1.7$ to 27$)$ & 8.4 (2.5 to 29$)$ \\
\hline No arm support (mouse) & 1 & - & - & - \\
\hline Arm support (mouse) $<50 \%$ time & $0.4(0.1$ to 1.3$)$ & - & - & - \\
\hline Arm support (mouse) $\geqslant 50 \%$ time & $0.7(0.3$ to 2.0$)$ & - & - & - \\
\hline Abnormal mouse position & $1.5(0.6$ to 3.6$)$ & - & - & - \\
\hline \multicolumn{5}{|l|}{ Keyboard time in hours per week } \\
\hline $0-4$ & 1 & 1 & 1 & 1 \\
\hline $5-9$ & $1.3(0.5$ to 3.2$)$ & $1.2(0.5$ to 3.0$)$ & $1.8(0.7$ to 4.8$)$ & $1.2(0.5$ to 2.9$)$ \\
\hline $10-14$ & $1.4(0.5$ to 3.7$)$ & $1.4(0.5$ to 3.6$)$ & $2.0(0.7$ to 5.8$)$ & $1.3(0.5$ to 3.4$)$ \\
\hline$\geqslant 15$ & $2.4(0.9$ to 6.7$)$ & $2.4(0.9$ to 6.6$)$ & $2.6(0.8$ to 8.4$)$ & $2.6(0.9$ to 7.3$)$ \\
\hline No arm support (keyboard) & 1 & - & - & - \\
\hline Arm support (keyboard) $<50 \%$ time & $1.1(0.5$ to 2.5$)$ & - & - & - \\
\hline Arm support (keyboard) $\geqslant 50 \%$ time & $1.2(0.6$ to 2.3$)$ & - & - & - \\
\hline Abnormal keyboard position & $1.2(0.6$ to 2.6$)$ & - & - & - \\
\hline Not satisfied with workplace design & $1.1(0.4$ to 2.7$)$ & - & - & - \\
\hline Work chair not adjusted & $0.8(0.1$ to 6.0$)$ & - & - & - \\
\hline Work desk not adjusted & $0.6(0.3$ to 1.4$)$ & - & - & - \\
\hline \multicolumn{5}{|l|}{ Psychosocial workplace factors } \\
\hline High demands & - & $1.8(1.0$ to 3.3$)$ & - & $1.9(1.0$ to 3.4$)$ \\
\hline Low control & - & $1.0(0.5$ to 1.7$)$ & - & \\
\hline Low social support & - & $1.1(0.6$ to 2.0$)$ & - & \\
\hline Time pressure & - & 1.8 (1.0 to 3.3 ) & - & $1.7(0.9$ to 3.1$)$ \\
\hline \multicolumn{5}{|l|}{ Personal characteristics } \\
\hline Negative affectivity & - & - & 1.8 (0.9 to 3.7$)$ & $1.6(0.8$ to 3.1$)$ \\
\hline Type A behaviour & - & - & $1.3(0.5$ to 3.0$)$ & - \\
\hline Age (10 years increment) & - & - & $1.4(1.0$ to 1.9$)$ & $1.4(1.1$ to 2.0$)$ \\
\hline Female gender & - & - & $1.9(0.9$ to 4.1$)$ & $2.2(1.1$ to 4.5$)$ \\
\hline $\mathrm{BMl}<19 \mathrm{~kg} / \mathrm{m}^{2}$ & - & - & $1.1(0.3$ to 4.7$)$ & - \\
\hline $\mathrm{BMI} \geqslant 27 \mathrm{~kg} / \mathrm{m}^{2}$ & - & - & $0.7(0.2$ to 2.9$)$ & - \\
\hline Poor social network & - & - & $1.3(0.5$ to 3.1$)$ & - \\
\hline High physical leisure activity & - & - & $0.6(0.3$ to 1.1$)$ & - \\
\hline Chronic disease & - & - & $2.0(0.8$ to 4.9$)$ & - \\
\hline Pain started after accident & - & - & $2.4(0.6$ to 10$)$ & - \\
\hline $\begin{array}{l}\text { Hosmer-Lemeshow's goodness of fit test with } 10 \\
\text { groups: } p \text { value }\end{array}$ & 0.70 & 0.66 & 0.76 & 0.14 \\
\hline
\end{tabular}

between the measured postural variables and hand/arm symptoms and disorders.

High job demands and time pressure predicted onset of forearm pain, whereas lack of control and lack of social support from supervisors and colleagues did not, and even the cross sectional associations were minor in the adjusted models. Gerr and colleagues ${ }^{12}$ found no effects of psychosocial factors, and did not include them in their final models. In comparison, our study benefits from a larger sample size with greater power to detect even small effects, which seem to be present for psychosocial workplace factors.

This study points towards duration of mouse device use and to a lesser extent keyboard use as the main work related risk factors for forearm pain, and preventive actions should include efforts to reduce weekly usage to less than 2025 hours.

\section{ACKNOWLEDGEMENTS}

Danish Medical Research Council; grant number: 9801292. Danish Ministry of Employment, via National Work Environment Authority; grant number 20000010486.

\section{Authors' affiliations}

A I Kryger, C F Lassen, J F Thomsen, S Mikkelsen, Department of Occupational Medicine, Copenhagen University Hospital, Glostrup, Denmark

J H Andersen, I Vilstrup, E Overgaard, Department of Occupational Medicine, Herning Hospital, Denmark

L P A Brandt, Department of Occupational and Environmental Medicine, Odense University Hospital, Denmark

\section{REFERENCES}

1 Macfarlane GJ, Hunt IM, Silman AJ. Role of mechanical and psychosocial factors in the onset of forearm pain: prospective population based study. BMJ 2000;321:676-9

2 Harrington JM, Carter JT, Birrell L, et al. Surveillance case definitions for work related upper limb pain syndromes. Occup Environ Med 1998:55:264-71.

3 Pritchard $\mathrm{MH}$, Pugh N, Wright I, et al. A vascular basis for repetitive strain injury. Rheumatology 1999;38:636-9.

4 Sharma SD, Smith EM, Hazleman BL, et al. Thermographic changes in keyboard operators with chronic forearm pain. BMJ 1997;314:118.

5 Greening J, Smart S, Leary R, et al. Reduced movement of median nerve in carpal tunnel during wrist flexion in patients with non-specific arm pain. Lancet 1999:354:217-18. 
6 Greening J, Lynn B. Vibration sense in the upper limb in patients with repetitive strain injury and a group of at-risk office workers. Int Arch Occup Environ Health 1998;71:29-34.

7 Jensen BR, Pilegaard M, Momsen A. Vibrotactile sense and mechanical functional state of the arm and hand among computer users compared with a control group. Int Arch Occup Environ Health 2002;75:332-40.

8 Punnett L, Bergqvist U. Visual display unit work and upper extremity musculoskeletal disorders: a review of epidemiological findings. Arbete och Halsa[16] 1997.

9 Sluiter JK, Rest KM, Frings-Dresen MH. Criteria document for evaluating the work-relatedness of upper-extremity musculoskeletal disorders. Scand J Work Environ Health 2001;27(suppl 1):1-102.

10 Hudak PL, Amadio PC, Bombardier C. Development of an upper extremity outcome measure: the DASH (disabilities of the arm, shoulder and hand) [corrected]. The Upper Extremity Collaborative Group (UECG) [published erratum appears in Am J Ind Med 1996;30:372]; Am J Ind Med 1996;29:602-8.

11 McConnell S, Beaton DE, Bombardier C. The DASH Outcome Measure user's manual. Toronto, Ontario: Institute for Work \& Health, 1999

12 Gerr F, Marcus M, Ensor C, et al. A prospective study of computer users: I. Study design and incidence of musculoskeletal symptoms and disorders. Am J Ind Med 2002;41:221-35.

13 Homan MM, Armstrong TJ. Evaluation of three methodologies for assessing work activity during computer use. AlHAJ 2003:64:48-55.

14 Marcus M, Gerr F, Monteilh C, et al. A prospective study of computer users: II. Postural risk factors for musculoskeletal symptoms and disorders. Am J Ind Med 2002;41:236-49.

15 Rayan GM. Compression neuropathies, including carpal tunnel syndrome. Clin Symp 1997:49:2-32. 